\title{
The color detection of two cucumber cultivars by NIR Spectroscopy
}

\author{
KUSUMIYATI", INDAH KURNIASARI, ADE RISTI OKTAVIA \\ Department of Agronomy, Faculty of Agriculture, Universitas Padjadjaran. Jl. Raya Bandung-Sumedang Km. 21, Jatinangor, Sumedang 45363, West \\ Java, Indonesia. Tel./fax.: +62-22-7796316, `email: kusumiyati@unpad.ac.id
}

Manuscript received: 15 October 2017. Revision accepted: 18 December 2017.

\begin{abstract}
Kusumiyati, Kurniasari I, Oktavia AR. 2017. The color detection of two cucumber cultivars by NIR Spectroscopy. Asian J Agric 1: 59-65. The color of cucumber fruit can be estimated as fruit quality trait. Genotypes and cultivars affect the color of cucumber fruit. The estimation can be done quickly and without tissue damage by NIR Spectroscopy. The purpose of this study was to determine the accuracy of color quality values with NIR and conventional methods. The experiment was conducted at Horticulture Laboratory, Faculty of Agriculture, Padjadjaran University in 2013. The color components observed were L, a, b, hue and chroma. The results indicated that the predicted component of cucumber color approximates values obtained from conventional methods. Based on the data obtained, the correlation coefficient ( $\mathrm{r}$ ) of color component approaches 1.00 and the standard calibration error (SEC) is low or close to 0.00 .
\end{abstract}

Keywords: Cultivar, Cucumis sativus L., fruit color, near-infrared spectroscopy, NIR

\section{INTRODUCTION}

One of the most important post-harvest activities on horticultural production is grouping fruit and vegetables based on certain criteria; this is referred to as grading. Grading criteria can be determined by physical appearance and internal chemical content inside the product. One of the judging criteria for the product is color. The color of the product is often associated with the level of maturity and taste of fruit, so that the criteria could be used for grading. Color pigment becomes internal content traits of the fruits and vegetables. In a simple way, green product shows high chlorophyll content, orange color shows high carotenoid, and purple-red color shows high flavonoid. The color change of the product may characterize changes in chemical content in horticultural products.

Cucumber is a popular horticultural product of Indonesia. Generally, the consumed cucumber is a young fruit and most of them will not enter the ripening phase. The cucumber fruit skin is generally green with white tinge at the lower end. The skin color of the cucumber will differ depending on the level of cucumber maturity. Cucumber fruit also changes color due to chlorophyll degradation. When associated with the color pigment, the cucumber initial color change (green on the greenish-white base toward the tip) becomes yellowish green at the base. Then the yellowish white toward the cucumber tip indicates the color degradation due to the metabolic process during storage. Visually, the color of cucumber skin can be seen directly.

Near-Infrared Spectroscopy (NIRS) is widely used for color measurements precisely and quickly at various fruit and vegetable products including cucumber. NIRS is a device that utilizes the near infrared wave color spectrum able to predict the internal quality of a product quickly and uniformly. Some research has been done to measure the internal quality of fruits and vegetables using NIRS such as grape (Guidetti et al. 2010), tomato (Nikbakht et al. 2011), Cavendish banana (Liew and Lau 2012), mango cv Gedong (Sugianti et al. 2012), Thai mango (Watanawan et al. 2014), apple (Eisenstecken et al. 2015). This research focused on the internal quality determination using NIRS.

This research will predict the color of the fruit of two cucumber cultivars. According to Mladenovic et al. (2013), fruit color trait is under the influence of dominant genes. Two cucumber cultivars are used in this study as a comparison. The prediction of cucumber color is done by using NIRS which will be compared with the assessment result using conventional method.

\section{MATERIALS AND METHODS}

\section{Material sources and tools}

The experiment was conducted at the Laboratory of Post-Harvest, Faculty of Agriculture, Padjadjaran University, Indonesia from June to August 2013. 300 fruits of cucumber (Cucumis sativus L.) cultivar "Bandana and Wulan" was used in this research. Portable near-infrared spectrometer (NirVana AG410, Integrated Spectronics Pty, Ltd, Australia), CIE L * a * b * box was used to measure the cucumber color. A set of computers for data processing using ISIS software (Integrated Spectronics Pty, Ltd, Australia), Microsoft Excel 2007 and Multivariate Unscrambler (version 9.7, CAMO, Oslo, Norway), Adobe Photoshop CS3 were used to analyze the NIRS data.

\section{Procedures \\ Fruit sampling}

The samples of cucumber fruit used in this study were cucumber cultivars Bandana and Wulan. They were obtained from a garden located in Curug Rendeng Village, Jalan Cagak Sub-district, Subang, West Java, Indonesia. The 7 to 14 days after flowering, cucumbers were selected 
as samples. Sampling and cucumber quality testing were performed ten times and each time was done for 60 samples in each cultivar. Before the test, fruits were stored for 12 hours at room temperature.

\section{NIRS analysis}

Portable NIRS was used to obtain the predicted values of cucumber fruit color components. The NIR wavelength range was 300-1100 nm with $2 \mathrm{~nm}$ interval. The halogen lamp light emitted directly by fiber optics to the fruit was placed behind the handle of the instrument.

Each cucumber was given a spectrum sensor of six different points at the base, middle, and end of the fruit. The duration of the one-time spectrum measurement was 5 seconds. The cucumber was placed on black cardboard during irradiation; black cardboard is required to cover the inclusion of light during the NIR measurements on the cucumber.

\section{Fruit color analysis}

Each cucumber fruit sample was inserted into the CIE $\mathrm{L}^{*} \mathrm{a}^{*} \mathrm{~b}^{*}$ box. Furthermore, the fruits were photographed by a digital camera that has been placed on top of the hole box CIE L* a* b* (Yam and Papadakis 2004).

\section{Calibration}

The estimation of cucumber color was performed using partial least squares (PLS) method. Calibration was the stage to determine the relationship between the color of cucumber absorbent data predicted by NIR and the result of conventional methods.

\section{Validation}

Validation aims to test the accuracy of the predicted calibration equations that have been produced. Validation was done by inserting different data samples with calibration data samples into the calibration equation.

\section{Data analysis}

The data obtained was analyzed using Microsoft Excel 2007, ISIS (Integrated Spectronics Pty, Ltd, Australia) and Multivariate Unscrambler (version 9.7, CAMO, Oslo, Norway) software. ISIS software was used to receive NIR spectra data and transformed into a computer. Microsoft Excel 2007 was used to process raw data obtained from NIR spectra.

After the spectral data is obtained then the next spectral data will be divided into two groups namely the calibration group and the validation group with different samples. The calibration and validation models were built using the partial least squares (PLS) method. All such processes were performed by multivariate data processing software available in Unscrambler software (version 9.7, CAMO, Oslo, Norway).

\section{RESULTS AND DISCUSSION}

The color measurements of cucumber fruit using Numerical color codes are $\mathrm{L}^{*}, \mathrm{a}^{*}, \mathrm{~b}^{*}$, hue, and chroma.
The $\mathrm{L}^{*}$ notation denotes reflected light that produces white, gray, and black achromatic color (0: black, 100: white). The $\mathrm{a}^{*}$ notation is chromatic color with red and green mixture which the $+\mathrm{a}^{*}$ (positive) value from 0 to +80 for red and-a* (negative) value from 0 to- 80 for green. The $\mathrm{b}^{*}$ notation is a mixture of blue with yellow, which the $+b^{*}$ (positive) value from 0 to +70 for yellow and-b* (negative) value from 0 to-70 for blue. Hue states the clarity of green color. The value of chroma expresses the gradations of moving colors from young to old (Zainal 2012).

\section{Measurement of cucumber fruit color conventional method}

The measurement of cucumber fruit color components was done by conventional method. Data quality component of cucumber test result of conventional method can be seen below (Table 1). Based on obtained data, cucumber cultivar Bandana and Wulan fruit color showed similarity. The-a* showed fruit color of both cultivars was green. The $b^{*}$ value was positive and lead up to yellow color. Measurements by using this conventional method fit with the cucumber color change from green to yellowish. The data presented in Table 1 shows the narrow distribution indicated by the standard deviation value. This data can be used as a comparison of cucumber fruit color prediction using NIR. Color testing using NIR aimed to obtain more objective data. Darrigues et al. (2008) stated that measuring color from digital images requires standardization and interpretation because digital devices use a color space that is not standardized, is nonlinear, and may vary between hardware devices and software applications.

\section{Measurement of cucumber fruit color non-destructive method using Near-Infrared (NIR)}

Measurement of the cucumber color component was performed with absorbance data in the 300-1100 nm wavelength range using the partial least squares (PLS) calibration method. Absorbance data is data obtained from the process of absorption of cucumber samples. Cucumber samples were divided into two groups, group one for the calibration stage and group two for the validation stage with each using different samples. The calibration regression to predict the cucumber yield quality component based on the absorbance data, is constructed by making the relation of the conventional fruit color quality component (reference data) to the NIR prediction value using the PLS method. A summary of non-destructive component cucumber component data using NIR is shown in Table 2.

The data presented in Table 2 is the color data of cucumber fruit $(\mathrm{L} * \mathrm{a} * \mathrm{~b} * \mathrm{~h} * \mathrm{C} *$ ) obtained by using NIR Spectroscopy. The value obtained from the sample showed a narrow data distribution. It can be seen based on the small standard deviation value. The cucumber color component has a standard deviation value below 10 except the standard deviation value of chroma. The low standard deviation value can be a reference that the data obtained is good. The data presented in Table 2 were used to construct calibration models based on NIR reflectance data correlations and cucumber color data with image processing. 
Table 1. Cucumber fruit color $\left(L^{*} a^{*} b^{*} h^{*} C^{*}\right)$ test result using conventional method

\begin{tabular}{cllllll}
\hline \multicolumn{2}{c}{ Component } & Sample & Min & Max & Mean & SD \\
\hline Color & L $^{*}$ & Bandana & 71,90 & 91,27 & 84,55 & 2,54 \\
& & Wulan & 77,13 & 90,67 & 84,90 & 2,02 \\
& Combined & 71,90 & 91,27 & 84,76 & 2,27 \\
& \multirow{2}{*}{$\mathbf{a}^{*}$} & Bandana & $-30,54$ & $-18,22$ & $-26,41$ & 2,20 \\
& Wulan & $-29,61$ & $-16,09$ & $-24,45$ & 2,72 \\
& Combined & $-30,50$ & $-16,10$ & $-25,30$ & 2,68 \\
& b* & Bandana & 22,87 & 47,50 & 39,24 & 3,49 \\
& Wulan & 24,67 & 66,70 & 36,45 & 3,70 \\
& Combined & 22,87 & 47,56 & 37,65 & 4,49 \\
& Hue & Bandana & $-63,19$ & $-45,00$ & $-55,68$ & 6,45 \\
& Wulan & $-64,24$ & $-50,79$ & $-56,13$ & 2,23 \\
& Combined & $-64,30$ & $-45,00$ & $-55,90$ & 4,65 \\
& Chroma & Bandana & 19,97 & 54,9 & 39,53 & 9,88 \\
& Wulan & 17,90 & 52,51 & 38,21 & 10,34 \\
& Combined & 17,90 & 54,90 & 38,81 & 10,15 \\
\hline
\end{tabular}

The best calibration regression was seen from the amount of data considered to represent the value range of the cucumber fruit color, the correlation coefficient (r) and the standard error (SE). The value of correlation coefficient (r) is used to know the contribution of free variables to related variables. Standard error (SE) is the difference between the expected value and the true value. The best correlation coefficient ( $r$ ) is a value close to 1.00 and close to 0.00 for standard error.

\section{Comparative analysis of conventional and non- destructive measurement data using Near-Infrared $\mathbf{L} *$ value prediction}

The best calibration regression on the predicted $\mathrm{L}^{*}$ values was obtained on both cultivars combined (Table 3 ). The number of samples at the calibration stage, as many as 217 samples, resulted in the value of correlation coefficient of 0.75 . Standard calibration error (SEC) was 1.30 showing the calibration regression prediction is built quite well. This suggests that the approximation of the $\mathrm{L}^{*}$ value by NIR is almost close to the conventional value. In the validation stage, 129 samples were used and the correlation coefficient value was 0.94 and the standard error validation value was 1.64 . This proves that the $L^{*}$ value of cucumber fruit can be well predicted using NIR. The comparison graph of $L^{*}$ NIR prediction value with $L^{*}$ value of the reference of conventional method results in calibration and validation stage can be seen in Figure 1.

The linear lines of the calibration stage and the validation of the estimated value of $\mathrm{L}^{*}$ cucumber in Figure 1 show uneven lines, but both points are in positive $X$ and positive $\mathrm{Y}$. This happens to be expected because it has a high error standard. On the other hand, graph of dispersion value of $\mathrm{L} *$ cucumber fruit at calibration stage for two cultivars can be seen in Figure 2. The higher $\mathrm{L}^{*}$ (Lightness) value showed brighter cucumber fruit color. $\mathrm{L}^{*}$ value color points distribution of two cultivars almost same, but the Wulan cultivar has higher brightness level than the Bandana cultivar.
Table 2. Cucumber fruit color $\left(L^{*} a^{*} b^{*} h^{*} C^{*}\right)$ test result using non-destructive method using NIR

\begin{tabular}{lllcccc}
\hline \multicolumn{2}{l}{ Component } & Sample & Min & Max & Mean & SD \\
\hline Color & L* & Bandana & 78,90 & 91,12 & 84,4 & 2,31 \\
& & Wulan & 79,14 & 97,85 & 86,69 & 4,66 \\
& & Combined & 79,44 & 89,37 & 84,33 & 1,51 \\
& \multirow{2}{*}{$\mathbf{a}^{*}$} & Bandana & $-30,74$ & $-18,29$ & $-26,66$ & 2,13 \\
& Wulan & $-30,98$ & $-19,89$ & $-25,37$ & 2,39 \\
& Combined & $-30,60$ & $-15,67$ & 26,13 & 2,47 \\
& \multirow{2}{*}{$\mathbf{b}^{*}$} & Bandana & 29,52 & 46,71 & 38,92 & 3,23 \\
& Wulan & 23,11 & 63,53 & 40,64 & 9,80 \\
& Combined & 25,17 & 46,09 & 37,36 & 4,06 \\
& Hue & Bandana & $-63,25$ & $-52,34$ & $-56,32$ & 2,43 \\
& Wulan & $-62,42$ & $-50,68$ & $-56,31$ & 2,14 \\
& Combined & $-61,14$ & $-52,02$ & $-56,14$ & 1,84 \\
& Chroma & Bandana & 20,89 & 55,74 & 37,74 & 10,17 \\
& Wulan & 17,92 & 51,46 & 37,46 & 9,39 \\
& Combined & 18,29 & 56,21 & 39,28 & 9,22 \\
\hline
\end{tabular}

Table 3. Calibration and validation of cucumber fruit $\mathrm{L}^{*}$ value analysis result

\begin{tabular}{lcccccc}
\hline \multirow{2}{*}{ Statistical description } & \multicolumn{2}{c}{ Bandana } & \multicolumn{2}{c}{ Wulan } & \multicolumn{2}{c}{ Combined } \\
& C & V & C & V & C & V \\
\hline Sample number & 90 & 79 & 107 & 93 & 217 & 129 \\
Coefisien correlation (r) & 0,94 & 0,85 & 0,97 & 0,79 & 0,75 & 0,94 \\
Standard error & 0,82 & 1,51 & 1,12 & 3,09 & 1,30 & 1,64 \\
\hline Note: C: Calibration, V: Validation & & & & &
\end{tabular}

Note: C: Calibration, V: Validation

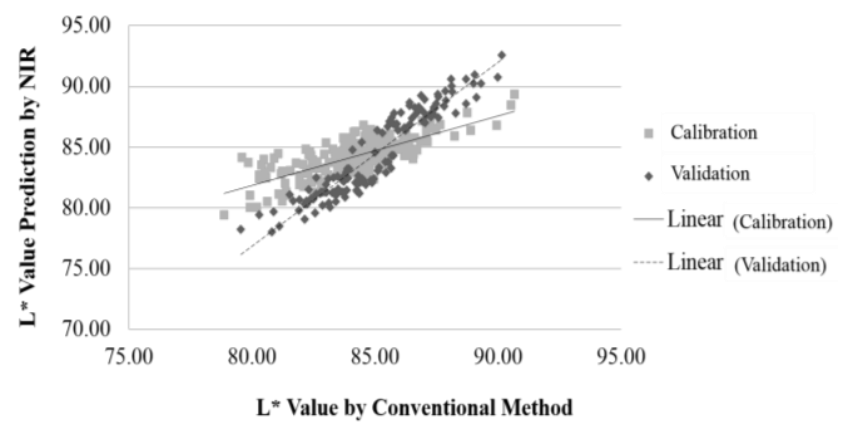

Figure 1. Comparison values of $\mathrm{L}^{*}$ cucumber fruit prediction NIR with value $L^{*}$ conventional method reference at the calibration and validation stage

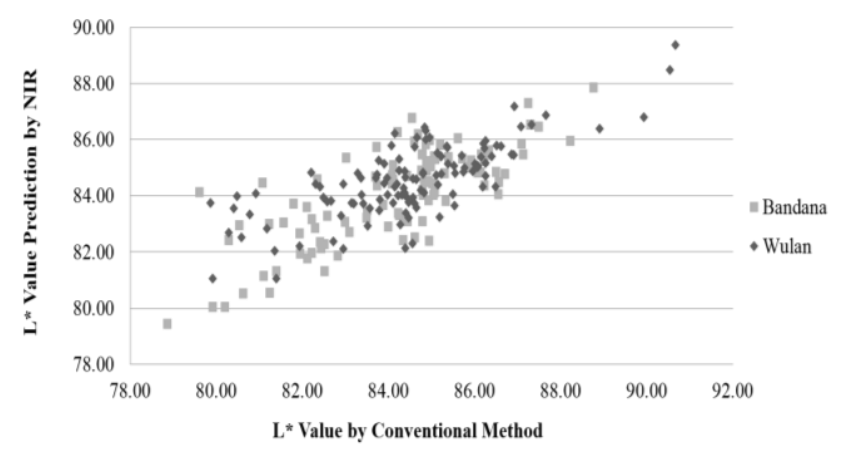

Figure 2. Dispersion value of $\mathrm{L}^{*}$ cucumber fruit at calibration stage of two cultivars 


\section{$a *$ value prediction}

The best calibration regression of the calibration and validation analysis result of the estimated value of $a^{*}$ cucumber fruit is shown in the cumulative data of the two cultivars compared with the data of each cultivar (Table 4). In the calibration stage of the combined cultivars, there were 227 samples used. The correlation coefficient value was 0.97 . Standard error calibration was obtained for 0.60 . The comparison graph of $a^{*}$ value NIR prediction with $a^{*}$ value reference of the conventional method results in the calibration and validation stage can be seen in Figure 3 .

At the validation stage, 121 samples were used and the correlation coefficient value for the combined data obtained value of 0.96 and the standard validation error of 0.98 . Judging from the value of correlation coefficient close to 1.00 and the error value is quite low then this result proves that the estimation of $\mathrm{a}^{*}$ value using NIR is quite accurate. This is in line with the research of Kusumiyati et al. (2008) which stated that high coefficient correlation (closed to 1) confirms a high validity for predicting the data in each parameter.

Figure 3 shows that the linear line of the calibration stage and the validation of the approximate value of $a^{*}$ cucumber fruit are almost parallel and are in the third quadrant $\mathrm{X}$ negative and $\mathrm{Y}$ negative. This shows the validation value is almost equal to the calibration value. The comparison graph of the value of $\mathrm{a}^{*}$ cucumber predictive NIR with $\mathrm{a} *$ value of conventional reference results in the two-cultivar calibration stage can be seen in Figure 4.

Figure 4 shows that the $a^{*}$ value of both cultivars is negative. The $a^{*}$ negative value indicates that fruit color was green fruit. The greater the negative value, the greener the color of the fruit. Seen in the picture above the value of $a^{*}$ on cucumber cultivar Bandana has a negative value larger than the Wulan cultivar. It can be concluded that the green color of Bandana cultivar is higher than the green color content value compared to Wulan cultivar. The use of two cucumber cultivars that have different genetic properties can increase the variation of the data so that the data range gets wider. It is suggested to increase the number of samples when dealing with heterogeneous samples for calibration with a larger range of values for the characteristic to be studied to increase: the heterogeneity of the sample, and the greater the range, the better the consistency of the calibration (Machado 2012; VIAVI 2015).

\section{b* value prediction}

Estimation of best $b^{*}$ value calibration regression result of calibration and validation data analysis was obtained on cumulative data of both cultivars (Table 5). The number of samples used was 202 samples. The value of both cultivar correlation coefficients obtained value of 0.97 , standard error calibration was obtained for 0.85 . This shows that the NIR predicted value is almost the same as the conventional method. The comparison graph of the value $b^{*}$ NIR prediction with the value of $b^{*}$ the reference of conventional method. Results of the calibration and validation stage can be seen in Figure 5 .
Table 4. Calibration and validation of cucumber fruit a* value analysis result

\begin{tabular}{lcccccc}
\hline \multirow{2}{*}{ Statistical description } & \multicolumn{2}{c}{ Bandana } & \multicolumn{2}{c}{ Wulan } & \multicolumn{2}{c}{ Combined } \\
& C & V & C & V & C & V \\
\hline Sample number & 147 & 74 & 164 & 80 & 227 & 121 \\
Coefisien correlation (r) & 0,94 & 0,72 & 0,98 & 0,95 & 0,97 & 0,96 \\
Standar error & 0,77 & 1,72 & 0,56 & 0,81 & 0,60 & 0,98 \\
\hline
\end{tabular}

Note: C: Calibration, V: Validation

Table 5. Calibration and validation of cucumber fruit $b^{*}$ value analysis result

\begin{tabular}{lcccccc}
\hline \multirow{2}{*}{ Statistical description } & \multicolumn{2}{c}{ Bandana } & \multicolumn{2}{c}{ Wulan } & \multicolumn{2}{c}{ Combined } \\
& C & V & C & V & C & V \\
\hline Sample number & 92 & 80 & 110 & 80 & 202 & 132 \\
Coefisien correlation (r) & 0,96 & 0,84 & 0,98 & 0,78 & 0,97 & 0,92 \\
Standard error & 0,88 & 2,51 & 1,74 & 5,77 & 0,85 & 1,61 \\
\hline
\end{tabular}

Note: C: Calibration, V: Validation

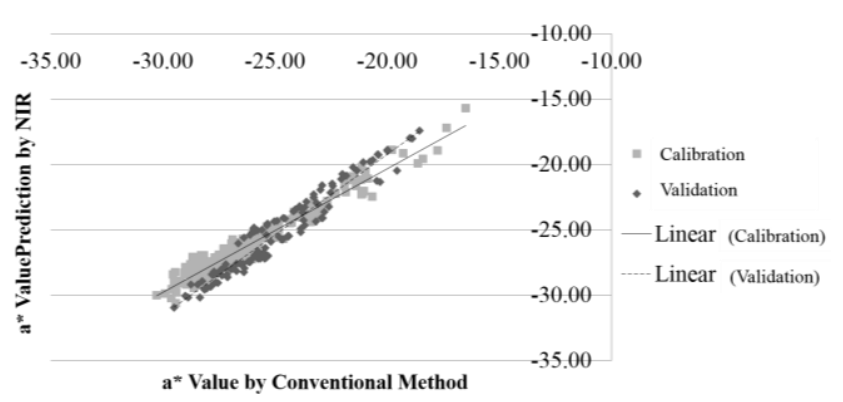

Figure 3. Graph of comparison values of $a^{*}$ cucumber fruit prediction NIR with value $a^{*}$ conventional method reference at the calibration and validation stage

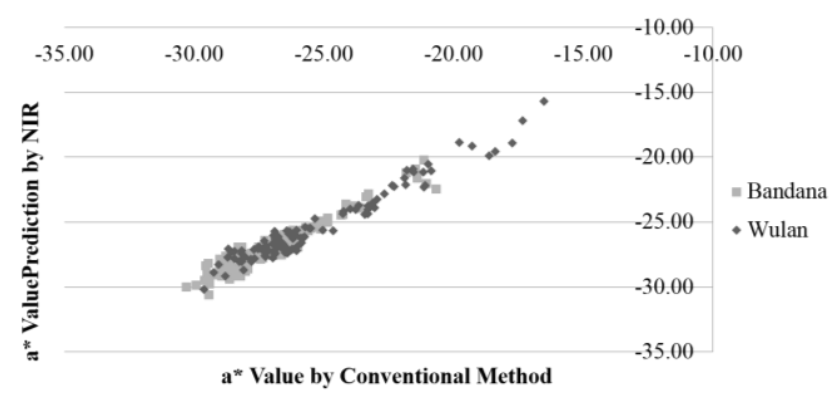

Figure 4. Dispersion value of $a^{*}$ cucumber fruit at calibration stage of two cultivars

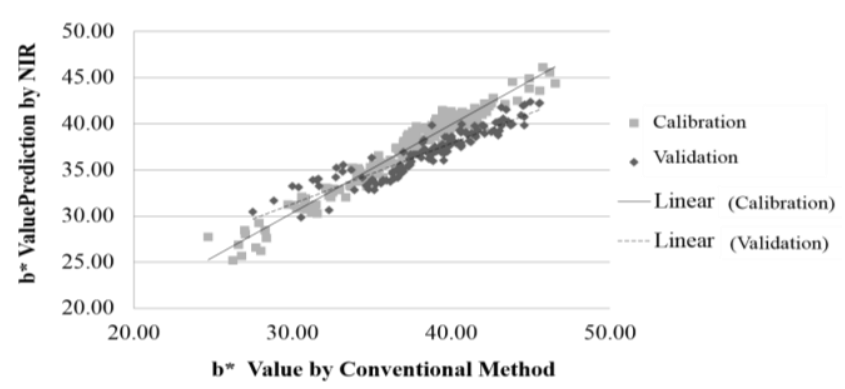

Figure 5. Graph of comparison values of $b^{*}$ cucumber fruit prediction NIR with value $b^{*}$ conventional method reference at the calibration and validation stage 
132 samples were used in the validation stage. Correlation coefficient value obtained for 0.92 and the standard error validation value of 1.61 . These results prove that NIRs can predict the value of $b *$ quite accurately. Figure 5 shows that the linear lines of the calibration stage and the validation of the predicted value of $b^{*}$ the two cultivars are almost parallel, which means the validation value is almost equal to the calibration value. Graph of value spread of $b^{*}$ cucumber fruit in the calibration stage for two cultivars data can be seen in Figure 6.

Figure 6 shows the $b^{*}$ value of both cultivars has a positive value indicating the color of the green fruit followed by the yellow color. It is seen that the value of $b^{*}$ in Bandana cultivar is higher than Wulan cultivar. This shows the cucumber samples of Bandana cultivars used in this study are much older. Old cucumber fruit has a yellowish green color. The use of two different cultivars and different levels of maturity can widen the range of data. Watanawan et al. (2014) stated there was fairly high correlation between NIR and $a^{*}$ or $b^{*}$ value which was obtained from increasing harvest maturity mangoes.

\section{Hue prediction}

The best calibration regression result of calibration and validation data analysis on hue estimation is found in the data of the two cultivars combined (Table 6). The calibration stage of the number of samples used was 247 samples; the correlation coefficient value was 0.84 Standard error calibration (SEC) obtained at 1.17. Judging from the value of the correlation coefficient and the standard error obtained, it can be expected that the calibration value obtained is quite high. The number of samples at the validation stage was 134 samples obtained correlation coefficient value of 0.82 and the standard error validation value of 1.93 . It can be concluded that hue value can be predicted well using NIR. The comparison graph of the hue prediction value of the NIR with the reference value of the conventional method results in the calibration and validation stage can be seen in Figure 7.

The hue estimation of cucumber fruit in the calibration stage and the validation of both cultivars have a linear line that is not parallel, but is in the same quadrant shown in Figure 7. Both cultivars have almost equal correlation coefficients of 0.84 for calibration and 0.82 for validation. Both lines are not aligned because they have a high error standard.

Graph of hue distribution of cucumber value at calibration stage for two cultivar data can be seen in Figure 8 . Figure 8 shows that the hue value of both cultivars (-) is negative. The hue negative value indicates that the clarity of the green color on the cucumber fruit. The points of the two cultivars overlapped. It can be concluded that the green color found in both cultivars has almost the same clarity value.

\section{Chroma value prediction}

Based on the number of samples, the value of correlation coefficient and standard error estimation of chroma value of cucumber fruit of calibration data analysis and calibration regression validation is the best found on the data of both cultivars combined. In the calibration stage, 205 samples were used. The value of correlation coefficient of both cultivars obtained a value of 0.95 standard error calibration obtained for 2.98. The stages of validation of the number of samples of 126 samples, obtained the value of correlation coefficient of 0.90 and the standard error of validation of 5.12 (Table 7).

Table 6. Calibration and validation of cucumber fruit hue value analysis result

\begin{tabular}{lcccccc}
\hline \multirow{2}{*}{ Statistical description } & \multicolumn{2}{c}{ Bandana } & \multicolumn{2}{c}{ Wulan } & \multicolumn{2}{c}{ Combined } \\
& C & V & C & V & C & V \\
\hline Sample number & 87 & 82 & 99 & 88 & 247 & 134 \\
Coefisien correlation (r) & 0,92 & 0,85 & 0,95 & 0,87 & 0,84 & 0,82 \\
Standard error & 1,00 & 2,67 & 0,69 & 1,96 & 1,17 & 1,93 \\
\hline
\end{tabular}

Note: C: Calibration, V: Validation

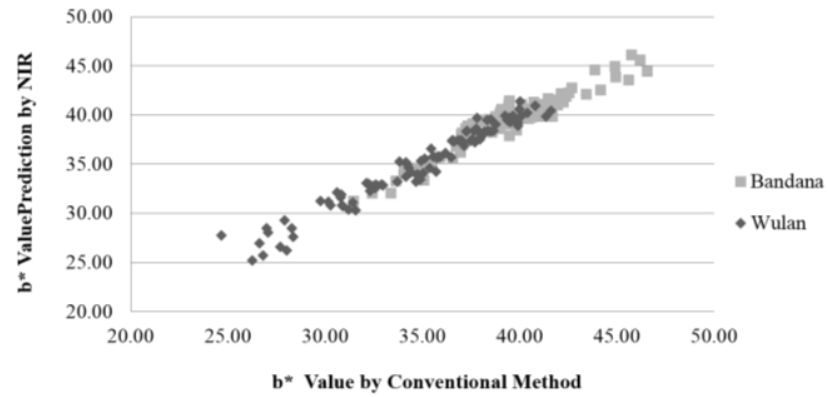

Figure 6. Dispersion value of $b^{*}$ cucumber fruit at calibration stage of two cultivars

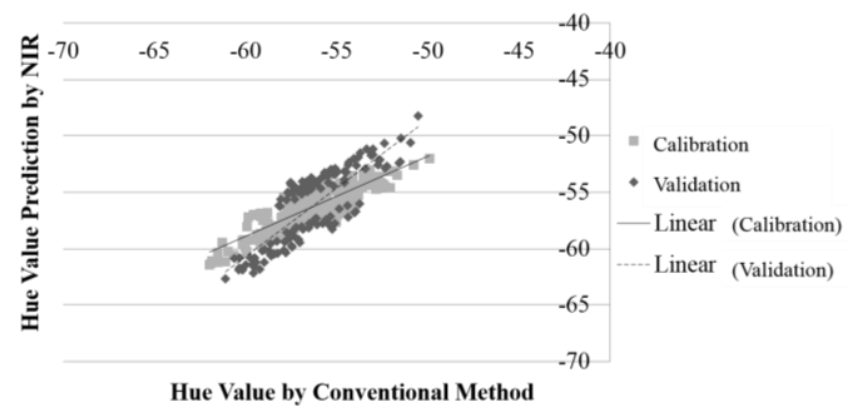

Figure 7. Hue comparison between prediction NIR with conventional method reference at the calibration and validation stage

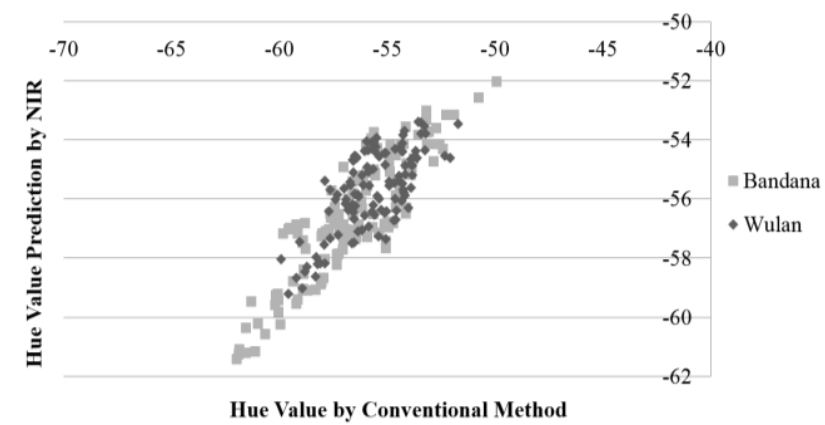

Figure 8. Dispersion hue of cucumber fruit at calibration stage of two cultivars 
Table 7. Calibration and validation of cucumber fruit chroma value analysis result

\begin{tabular}{lcccccc}
\hline \multirow{2}{*}{ Statistical description } & \multicolumn{2}{c}{ Bandana } & \multicolumn{2}{c}{ Wulan } & \multicolumn{2}{c}{ Combined } \\
& C & V & C & V & C & V \\
\hline Sample number & 102 & 85 & 112 & 96 & 205 & 126 \\
Coefisien correlation $(\mathrm{r})$ & 0.98 & 0.82 & 0.97 & 0.95 & 0.95 & 0.90 \\
Standar error & 1.75 & 5.74 & 2.31 & 4.14 & 2.98 & 5.12 \\
\hline
\end{tabular}

Note: C: Calibration, V: Validation

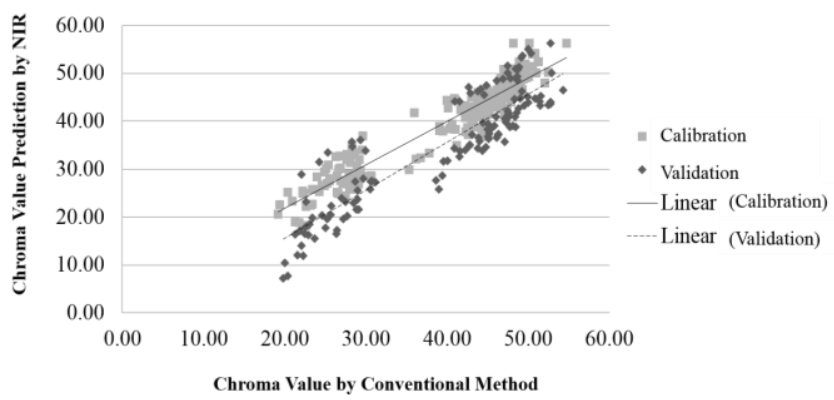

Figure 9. Chroma comparison between prediction NIR with conventional method reference at the calibration and validation stage.

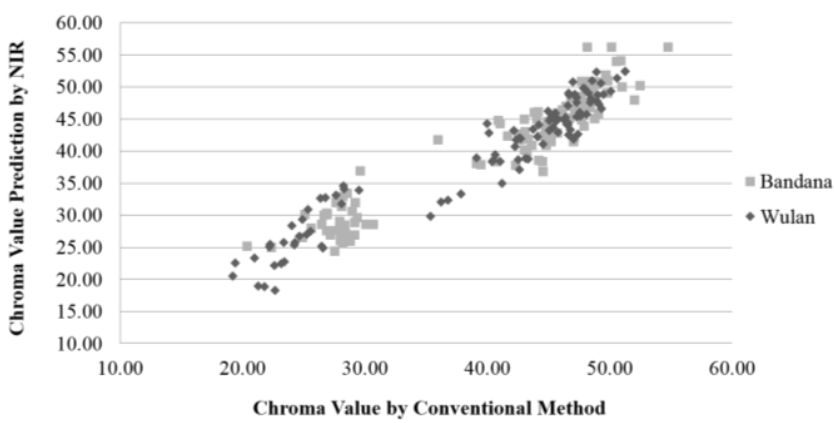

Figure 10. Dispersion of chroma cucumber fruit at calibration stage of two cultivars

Based on the high standard of the validation error, it shows that chroma value is not well predicted by NIR. Chroma predictive value comparison chart of NIR with reference value of the conventional method of chroma at the calibration and validation stage can be seen in Figure 9.

The linear line of the calibration and validation stages on the approximate value of the cucumber chroma appears parallel and positive (Figure 9). It shows that the calibration value is almost equal to the validation value. The comparison chart of the chroma value at the calibration stage for the two-cultivar data can be seen in Figure 10.

Chroma value shows gradations of green cucumber color from young to old. Figure 10 shows that there are empty spots on both cultivars. This shows that the gradations of cucumber green color from young to old in Bandana and Wulan cultivars are less visible, so the standard error obtained is quite high. Additional samples are required to fill the void of the graph above to reduce the high error standard. According to Dardenne (2009), the influence of sample number is important. The number of samples will affect error in predictions.

In conclusion, the results that have been described previously show the color component analysis of the nondestruction method using NIR and conventional method on cucumber fruit cultivar Bandana and Wulan. The L, a, b, and hue can be predicted using NIR well. Unlike other components, the chroma value in this study was not well predicted. This is certainly different from the research done by Sanchez et al. (2012) that said modified partial least squares analysis confirmed the feasibility of NIRS for predicting color-related external quality parameters ( $\mathrm{L} * \mathrm{a} *$, and $\mathrm{C} *)$. Precisely predictions can occur because of some things such as improper absorbance values used or characteristics of the fruit itself. Based on the data, it can be concluded that the non-destructive color cucumber component using NIR has accuracy value like the conventional method. In the observed color component, the correlation coefficient (r) approaches 1.00, and the standard calibration error (SEC) is low or close to 0.00 .

\section{ACKNOWLEDGEMENTS}

We would like to thank the Directorate General for Higher Education of Indonesia who has funded and supported the higher education research project.

\section{REFERENCES}

Dardenne P. 2009. Some considerations about NIR spectroscopy: closing speech at NIR-2009. Belgium. http://www.impublications.com/ content/ some-considerations-about-nir-spectroscopy

Darrigues A, Jack H, Esther VDK, David MF, Nancy D, Simon G. 2008. Tomato analyzer-color test: A new tool for efficient digital phenotyping. J Amer Soc Hort Sci 133: 579-586.

Eisenstecken D, Panarese A, Robatscher P, Huck CW, Zanella A, Oberhuber M. 2015. Near-Infrared Spectroscopy (NIRS) and chemometric approach to improve apple fruit quality management: A case study on the cultivars "Cripps Pink" and "Braeburn". Molecules 20: $13603-13619$

Guidetti R, Beghi R, Bodria, L. 2010. Evaluation of grape quality parameters by a simple VIS/NIR system. Food \& Process Engineering Institute Division of ASABE 53: 1-8.

Kusumiyati, Takayoshi A, Shigeyasu Y, Sheishi K, Tetsuya T. 2007. Evaluation of tomato quality on tree and after harvesting using portable NIR Spectroscopy. J Soc Agric Struct Japan 38: 117-126.

Liew CY, Lau CY. 2012. Determination of quality parameters in Cavendish banana during ripening by NIR spectroscopy. Intl Food Res J 19: 751-758.

Machado NP, José CF, Simone PG, Débora LB, Mateus SP, Juliano DS. 2012. Pear quality characteristics by Vis / NIR spectroscopy. Acad Bras Cienc 84: 853-863.

Mladenovic E, Berenji J, Hiel K, Čukanović J. 2013. Inheritance of warty fruit texture and fruit color in bottle gourd [Lagenaria siceraria (Molina) Standl.]. Genetika 45: 27-432.

Nikbakht AM, Hashjin TT, Malekfar R, Ghobadian B. 2011. Nondestructive determination of tomato fruit quality parameters using Raman Spectroscopy. J Agric Sci Technol 13: 517-526.

Sánchez MT, Habaa MJD, López MB, Novales JF, Varo AG,Marín DP. 2012. Non-destructive characterization and quality control of intact strawberries based on NIR spectral data. J Food Eng 110: 102-110.

Sugianti C, Hasbullah R, Purwanto YA, Setyabudi DA. 2012. Kajian pengaruh iradiasi dosis $0.75 \mathrm{kGy}$ terhadap kerusakan dingin (chilling 
injury) pada buah mangga gedong selama penyimpanan. Jurnal Teknik Pertanian Lampung 3 (2): 195-204. [Indonesian]

VIA VI. 2015. The Effects of Sample Presentation in Near-Infrared (NIR) Spectroscopy. https://www.viavisolutions.com/enus/literature/effects-sample-presentation-near-infrared-nirspectroscopy-application-notes-en.pdf

Watanawan C, Wasusri T, Srilaong V, Kanlayanarat S. 2014. Nearinfrared spectroscopic evaluation of fruit maturity and quality of export Thai mango (Mangifera indica L. var. Namdokmai). Intl Food Res J 21: 1109-1114.

Yam KL, Papadakis SE. 2004. A simple digital imaging method for measuring and analyzing color of food surfaces. J Food Eng 61: 137142.

Zainal PW, Ahmad U, Purwanto YA. 2012. Deteksi chilling injury pada buah mangga gedong gincu dengan menggunakan Near Infrared Spectroscopy. Jurnal Keteknikan Pertanian 26 (1): 61-68. [Indonesian] 